\title{
Errores comunes que se producen en la escritura de los artículos científicos
}

$\mathrm{C}$ omo director de la RESED, he notado a lo largo de los años de revisar cientos de artículos, la repetición de algunos errores relacionados con la estructura de los artículos que recibimos. A continuación y de forma sucinta enumero algunos de los errores más comunes.

Un artículo bueno pero mal escrito retrasa o incluso puede impedir la aceptación y el proceso de publicación del mismo. Esto, por supuesto, no es una lista completa, porque cada revista tiene sus normas especificas que siempre hay que consultar y seguir, pero puede servir de ayuda cuando queremos publicar lo que hemos hecho.

El título del artículo es muy importante y no debe ser ni demasiado largo ni demasiado corto, además debe coincidir precisamente con el diseño del estudio. No debe incluir abreviaturas, jerga, o ironías a expensas de la claridad. En definitiva el título debe describir el estudio completamente.

Tras el título debemos prestar mucha atención al resumen, sabemos que la mayoría de los lectores es todo lo que van a leer de nuestro artículo, por ello el Resumen debe contener todo lo fundamental del artículo, además los repositorios muchas veces solo publican los resúmenes. Por ello los resultados que describimos en el Resumen, no son los mismos que los resultados reportados en el apartado de Resultados donde son más amplios, lo mismo sucede con la descripción del método y la discusión. Hay que estar muy atento a no superar el límite de palabras establecidos por las normas de la revista. Muchas revistas (como la RESED) exigen que el Resumen sea estructurado, es decir con sus apartados correspondientes, otras permiten un texto libre, (las menos).

El artículo empieza siempre con la introducción, cuya misión es describir el propósito y objetivo del estudio, su importancia y originalidad. Solo debe contener material relacionado con el estudio. No debe contener nada de lo que describamos en las otras secciones del artículo. Debe ser breve pero interesante para incitar al lector a seguir leyendo el resto del artículo.

Material y métodos, algunos de los errores más comunes son: no haber utilizado algunos de los métodos que se describen. No explicitar el método de tal modo que el estudio pueda ser replicado exactamente. Mención aparte es la descripción del método estadístico utilizado, algo que cada vez se valora más. No se trata de decir la versión del paquete estadístico utilizado, ni la marca del ordenador que hemos utilizado, sino de describir las variables y los métodos utilizados que demuestren la "veracidad" de lo encontrado. Obviamente no se pueden describir métodos no relacionados con los resultados.

Los resultados es la parte clave del artículo y los errores más comunes son: describir los resultados de una manera incompleta, o dar resultados de otros estudios, repetir en el texto la información que se muestra en las tablas y figuras, o discutir los resultados (esto es muy común), esto solo se hace en la discusión, que es la parte final y más difícil de escribir, a veces esta es parcial y omite los hallazgos de otros estudios previos, o no explica resultados claves. Es muy valorado que el autor describa las limitaciones del estudio, que no son las especulaciones que nos gustaría contar. No debe incluir información no relacionado con el estudio o hacer referencias obsoletas 
o que no vienen al caso. Habitualmente son demasiado extensas y la tendencia es a la brevedad y a que tengan un hilo conductor muy lógico.

Finalmente aunque no todas las revistas lo piden o lo admiten, si el artículo acaba con unas conclusiones, estas deben solo reafirmar el contenido de las otras secciones del manuscrito. No debe incluir declaraciones no respaldadas por el estudio. Por tanto solo debe resaltar lo probado en nuestro estudio y no en otros estudios. Frecuentemente los autores incluyen información innecesaria.

Así que si queremos que nuestros artículos sean más fácilmente aprobados, no solo tienen que ser originales y aportar nuevos conocimientos científicos, sino que debemos esforzarnos en que estén bien estructurados y redactados, de lo contrario es fácil que sean rechazados a pesar de ser muy válidos.

L. M. Torres Morera

Servicio de Anestesia-Reanimación y Tratamiento del Dolor. Hospital Universitario Puerta del Mar. Director de la Revista de la Sociedad Española del Dolor 